note that the Council have recognized the necessity of obtaining from all the licensing corporations a return showing the regulations in force as to the teaching of ophthalmology, and this mandate is in process of being complied with. That is something to the good, but it does not go far enough. The suggestion may be made that if the Council were to approve of a regulation requiring every examining Board to include in its constitution one ophthalmic surgeon, it is certain that the speeding up of ophthalmological teaching in this country would immediately follow. A student's study of a subject is largely dependent upon his examinational interest in it. $\mathrm{He}$ is naturally disposed to shirk anything upon which an examinational knowledge is not directly insisted. Ophthalmology is one of these subjects; a perfunctory compliance with the General Medical Council's regulation, by which a certificate for attendance is granted, may only endow him with a distinguishable negligent knowledge of diseases of the eye, and yet, despite this, he is able to obtain his qualification to practise. Having regard to the importance of ophthalmology as a special branch of medicine, the ophthalmologists are making a just claim for its examinational recognition."

\title{
British Ophthalmology
}

It is impossible to over estimate, at the present moment, the importance of re-organizing on a broad basis the Schools of Ophthalmology in the British Isles. Never has there been such an opportunity as that now offered, both in scope and promise of improving our speciality, if all British ophthalmic surgeons realizing the necessity for reconstruction-will throw themselves whole-heartedly into working out a thorough scheme with zeal and energy.

We should ensure, first, that the new generation of surgeons shall be fully trained, and, secondly, that treatment both preventive and curative for hospital and private patients shall be more fully organized.

The admirable report of the Council of British Ophthalmologists, published in the last number of this Journal, should give great impetus to the teaching of ophthalmology all over the British Isles. The need of some recognized diploma or degree in ophthalmology, which must be obtained by a surgeon before he is admitted as a candidate for any important ophthalmic post, has long been felt.

In the past most of the leading medical schools and special hospitals have required merely that candidates for ophthalmic posts shall be Fellows of the Royal College of Surgeons of England, and have insisted upon no guarantee that such candidates have been 
through any complete course of ophthalmology. This is quite inadequate.

If systematic courses of ophthalmogy were developed, the examining bodies, which up to the present have failed to support the interests of this branch of surgery, might then be stimulated to institute special examinations for degrees and diplomas carrying the weight of the higher surgical qualifications. In the scheme of reconstruction candidates who have never been through a complete curriculum should not be eligible to hold important teaching posts. At the present time a teacher may, for instance, not have taken any pathological course, and may, therefore, be quite incapable of correlating the pathological with the clinical aspects of disease, which is the only true basis of sound practice.

Another point of great importance is that the public has no means of judging the qualifications of those practising ophthalmic surgery. Surgeons with meagre ophthalmic knowledge may settle in fashionable quarters and obtain an influential clientèle, with the inevitable result that serious mistakes are made and discredit is thrown upon British ophthalmology. If a Diploma were insisted upon the absence of such qualifications would be a warning to the public.

Considerable energy is already being shown in the development of special courses, a movement which needs strengthening and co-ordinating. If an enthusiastic effort is made now, there is no reason why the British School of Ophthalmology should not take the same high place of popularity that it held in earlier days.

For years to come the ophthalmic schools of Austria and Germany will not be frequented by the students of the Allied nations who, in the past, have been attracted to them by the greater organization of the classes of instruction. There is no reason why these should not study in the British schools and find the benefit of the more practical methods adopted in this country, provided that complete organization of instruction is combined with thorough and practical clinical work.

Ophthalmology has always been recognized as one of the most important specialties, and the whole profession would welcome an energetic movement of this kind.

Yet not only must the training of ophthalmic surgeons be improved but also the treatment of patients. The British public should be led to recognize that a British opinion is as valuable, if not more valuable, than one obtained elsewhere.

One of the chief difficulties is the absence of high-class institutional treatment for the well-to-do patients. The nursing home system in this country is faulty, and spas and health resorts need to be reorganized and developed to make them both more efficient and attractive. This principle is no less important in our hospital practice. 
One of the lessons of the war is the wonderful saving in time and man-power that was effected by institutional treatment from the beginning of such cases as corneal ulcer, iritis, etc. This lesson should be applied to civilian practice and to civil hospital patients. At present the triumphs of in-patient treatment are obtained with cataract and glaucoma patients who have often come to the end of their active life. There is a tendency to fill the beds with operation cases, so that no room is available for many cases requiring treatment. Institutional treatment at an early stage might save many a clear pupillary area of the cornea, and might leave an eye affected with iritis ready to resist any subsequent recurrence, unhampered even by a single adhesion. By sending these cases to be treated in a haphazard way in their own homes both time and power are lost.

Should not all leading 'ophthalmic hospitals now have convalescent homes, such as the army hospitals have had ${ }^{\bullet}$ abroad, where complete recovery can take place in fresh air, and under skilled attention, combined with adequate occupation and amusement ? If these homes were established to receive the convalescents the present hospitals would still be able to restore sight to the aged by operation, while all the cases in the acute stages of disease could at once, without overcrowding, be admitted for institutional treatment and passed on to the convalescent home for complete recovery under more salubrious surroundings than can be afforded by city hospitals.

Such homes may be difficult to obtain at the moment owing to expense, but it would be well to have a complete and concrete policy to put forward should the voluntary hospitals, in the near future, be taken over wholly or in part by the State.

\section{REPORT OF THE COUNCIL OF BRITISH OPHTHALMOLOGISTS}

\section{On the visual requirements of persons licensed to drive mechanically propelled vehicles on public roads}

THE following report is the result of an enquiry conducted during the early months of the year, 1919, by a Committee appointed by the Council of British Ophthalmologists. The Council was impressed by the increasing number of accidents caused by motor traffic, and desired to ascertain to what extent these might be due to defective vision on the part of drivers. Unfortunately, as will be seen from the report, statistics on this point are meagre. As matters at present stand, the only qualification required for obtaining a licence to drive a motor vehicle, other than a public conveyance, is that the applicant must be 17 years of age, and it is 